\title{
Evaluation of In Situ Rainwater Harvesting as an Adaptation Strategy to Climate Change for Maize Production in Rainfed Africa
}

\author{
S. Lebel ${ }^{1,2} \cdot$ L. Fleskens ${ }^{1,3} \cdot$ P. M. Forster ${ }^{2}$ • \\ L. S. Jackson ${ }^{2} \cdot$ S. Lorenz ${ }^{1,2}$
}

Received: 17 September 2014 / Accepted: 2 August 2015 /

Published online: 9 August 2015

(C) The Author(s) 2015. This article is published with open access at Springerlink.com

\begin{abstract}
Stabilizing smallholder crop yields under changing climatic conditions in subSaharan Africa will require adaptation strategies focused on soil and water management. Impact studies of climate change on crop yields often ignore the potential of adaptation strategies such as rainwater harvesting (RWH). While RWH is bringing benefits to agricultural systems today, it is still unclear which regions could increasingly benefit from RWH under changing climatic conditions. Here we employ a continental scale modelling strategy using the latest CMIP5 data and explicitly take into account design factors of RWH to show that it is a valuable adaptation strategy to climate change in Africa for maize (Zea mays L.). We find that RWH can bridge up to $40 \%$ of the yield gaps attributable to water deficits under current conditions and $31 \%$ under future (2050s) climatic conditions during the main growing season for maize, hence providing an alternative to irrigation from scarce or inaccessible groundwater resources. RWH could increase maize yields by $14-50 \%$ on average for the 2050 s across Africa, by bridging water deficits. While in situ RWH strategies show great biophysical potential as an adaptation strategy to climate change, there remain locally specific barriers to their adoption, which will need to be addressed to ensure their successful implementation at a larger scale.
\end{abstract}

Keywords Rainwater harvesting · Climate change adaptation - Climate change impacts

Electronic supplementary material The online version of this article (doi:10.1007/s11269-015-1091-y) contains supplementary material, which is available to authorized users.

\section{S. Lebel}

eesl@leeds.ac.uk

1 Sustainability Research Institute, School of Earth and Environment, University of Leeds, Leeds LS2 9JT, UK

2 Institute for Climate and Atmospheric Science, School of Earth and Environment, University of Leeds, Leeds LS2 9JT, UK

3 Soil Physics and Land Management Group, Wageningen University, Wageningen, The Netherlands 


\section{Introduction}

Rainfed agriculture remains to this day the predominant form of crop production in sub-Saharan Africa, with at its highest $21 \%$ of the total cropland harvested irrigated in Southern Africa, and a meagre $1 \%$ irrigated in West Africa (Portmann et al. 2010). The expansion potential for irrigation is very limited and hence solutions to increase food security and decrease poverty will have to rely on alternative water management strategies (Rockström and Falkenmark 2015). With a changing climate, dryland African farmers who subsist from rainfed agricultural systems will have to cope with increased risk arising from more frequent extreme events and poor intraseasonal rainfall distribution (Barros et al. 2014). Since rainfall patterns are the main factor steering crop productivity in Africa (Muller et al. 2011), these changes will be detrimental to food production (Cline 2007). However, the potential (and current) use of adaptation strategies to overcome these challenges is rarely taken into account in impact studies. Several adaptation measures are being promoted to cope with a changing climate, such as the use of different crops or crop varieties, soil conservation, changing planting dates, and irrigation (Bryan et al. 2009), but these may not all be viable choices for smallholder farming either due to their high costs, technical restrictions, or even cultural limitations (Adger et al. 2012).

In areas such as the Sahel, where it is estimated that only $10-15 \%$ of rainwater is used productively for plant growth (Breman et al. 2001), rainwater harvesting (RWH) could help mitigate the impacts of climate change on crop production. In situ RWH strategies, such as planting pits or stone bunds implemented at the field level (Online Resource 1), act to shift a fraction of surface runoff water to productive purposes by storing water in the form of soil moisture (Rockström et al. 2002). This entails that water is made directly available to crops, and does not require being re-routed using pumps. They are not aimed at directly improving water use efficiency, but rather at reducing the variability in potential and actual crop yields (Fox and Rockström 2000). By increasing the water holding capacity of highly degraded soils, RWH can also reduce crop damage due to soil degradation by water erosion. Moreover, RWH reduces the susceptibility of crops to the adverse effects of frequent dry spell events (Barron et al. 2003; Rockström et al. 2002), and has the ability to reduce inter-seasonal crop yield variability associated with erratic climatic patterns.

Numerous studies have investigated the siting of RWH systems under current climatic conditions (e.g. Jasrotia et al. 2009; Kadam et al. 2012), but most fail to assess the performance of these systems under changing climatic conditions. Moreover, they often provide dataintensive, site-specific, and crop-independent analyses, which can be inadequate to inform national-level policy making. While we know that RWH can bring benefits to rainfed agricultural systems today, it is still unclear which regions could increasingly benefit from RWH under changing climatic conditions.

Here we quantify, at the continental scale, the potential of RWH to reduce water deficits experienced by a maize (Zea mays L.) crop under present and future climate projections for the 2050s across Africa for increasing radiative forcings (RCP8.5). Under this scenario, the 2050s would be the first period where climate would depart from its current variability, and therefore lead to unprecedented environmental conditions (Mora et al. 2013). Maize is the most widely grown crop in Africa, especially in Southern Africa where it represents $50 \%$ of the harvested area (Portmann et al. 2010), and is one of the crops most often found to be produced with the help of in situ RWH. Its production is expected to continue to grow in the future. Using a gridbased empirical approach based on freely available datasets, including the latest data from the Coupled Model Intercomparison Project Phase 5 (CMIP5), we establish water deficits 
experienced by maize on a monthly basis. Then, we evaluate the amount of water that can physically be harvested within each grid cell in Africa. Different than previous analyses, our analysis explicitly takes into account local biophysical characteristics to evaluate RWH capacity, as opposed to assuming that a constant fraction of runoff can be harvested at any location (e.g. Rost et al. 2009). Finally, we estimate RWH benefits on crop yields under current and future climatic conditions.

\section{Materials and Methods}

\subsection{Climate Input Data}

Three General Circulation Models (GCMs) from CMIP5 were selected based on the availability of model output at the time of beginning this study, and model ability to reproduce realistic surface runoff. The models selected represent three modelling research groups: BCCCSM1-1, MIROC5, and NorESM1-M. Selecting three different GCMs illustrates the range of projections present within the CMIP5 dataset, with projections from each model considered to have an equal likelihood of realisation in the future. The data was extracted for two experiments (Historical and RCP8.5 respectively), with a focus on the medium-term projections for the highest radiative forcings pathway RCP8.5 (2046-2065), and a 20-year historical time period (1986-2005). All CMIP5 data was regridded to $0.5^{\circ} \times 0.5^{\circ}$ latitude/longitude spatial resolution to allow inter-model comparison. Monthly means for the 20 -year periods were calculated for temperature, precipitation, solar radiation, and surface runoff from all three GCMs. Figure 1 provides a first glimpse into CMIP5 projections for precipitation and potential evapotranspiration. Evaporation increases in all models, while changes in rainfall are less consistent. Hence, increasing rainfall could not directly be associated with better crop yields, as crop water requirements are simultaneously increasing as well.

\subsection{Methodology}

A simple empirical approach to the determination of RWH potential was developed based on freely available datasets. The aim was to provide a spatially-relevant overview of agricultural water management requirements for national-scale policy-making, in regions where higherresolution data can be scarce. A schematic representation of the methodological process is presented in the Online Resource 2.

\subsubsection{Estimating Crop Water Requirements}

Water requirements of different crops vary both in quantity and temporal distributions. Crop water requirements were estimated for the 20-year historical and future monthly climatic averages from the three GCMs across Africa. Crop water requirements, equivalent to crop evapotranspiration here $\left(\mathrm{ET}_{\mathrm{c}}\right.$ ), are defined by Allen et al. (1998):

$$
E T_{c}=K_{c}^{*} E T_{0}
$$

Where $\mathrm{K}_{\mathrm{c}}$ is crop factor (dimensionless, see below) and $\mathrm{ET}_{0}$ represents reference evapotranspiration. While $\mathrm{ET}_{0}$ remains an important variable in hydrological models, it is not always 


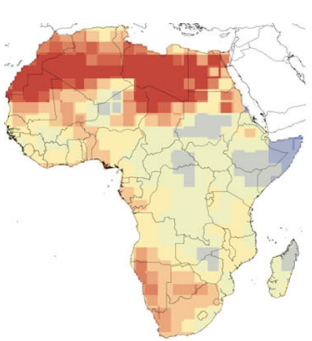

(a)

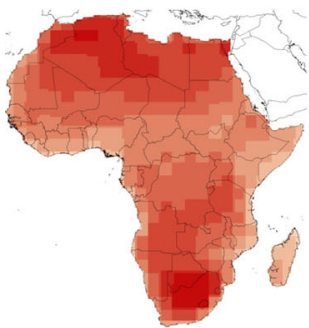

(d)

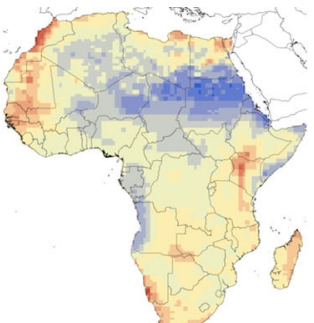

(b)

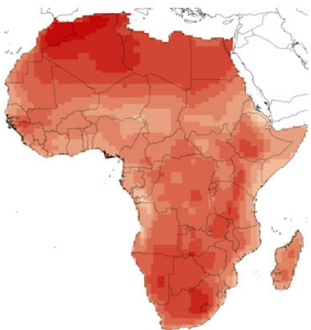

(e)

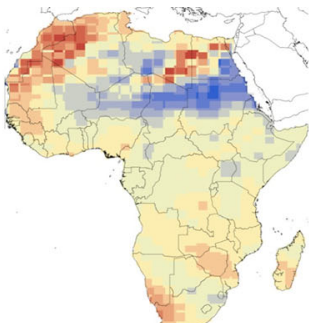

(c)

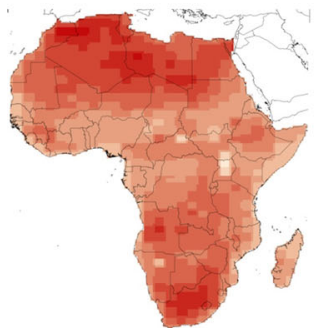

(f)
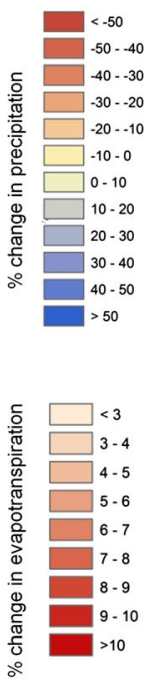

Fig. 1 Projected percentage changes in precipitation $(\mathbf{a}, \mathbf{b}, \mathbf{c})$ and potential evapotranspiration $(\mathbf{d}, \mathbf{e}, \mathbf{f})$ for BCCCSM1-1 (a,d), MIROC5 (b,e), and NorESM1-M (c,f) between the 1986-2005 and 2046-2065 (RCP8.5) periods. While the climate models selected here do not fully agree on the magnitude or direction of change in precipitation over Africa, there is a general agreement that potential evapotranspiration will be increasing over the entire continent by the 2050 s

calculated directly in climate models. In order to estimate $\mathrm{ET}_{0}$, most hydrological models use the data intensive and physically-based Penman-Monteith equation. Simpler equations have been shown to be as good, and sometimes better, at evaluating $\mathrm{ET}_{0}$ compared to the PenmanMonteith equation (Kay and Davies 2008). Here $\mathrm{ET}_{0}$ was estimated from the CMIP5 data using the approach suggested by Oudin et al. (2005) (Eq. 2):

$$
\begin{gathered}
E T_{0}=\frac{R_{e}}{\lambda \rho_{w}} \frac{T_{a}+5}{100} \text { if }\left(T_{a}+5\right)>0 \\
E T_{0}=0 \text { otherwise (negatives values are being reset to zero) }
\end{gathered}
$$

Where $R_{e}$ is the extraterrestrial radiation $\left(\mathrm{J} / \mathrm{m}^{2} / \mathrm{s}\right), \lambda$ is the latent heat flux $\left(2.45 \times 10^{6} \mathrm{~J} / \mathrm{kg}\right), \rho_{\mathrm{w}}$ is the density of water $\left(1000 \mathrm{~kg} / \mathrm{m}^{3}\right)$, and $\mathrm{T}_{\mathrm{a}}$ is the mean monthly air temperature $\left({ }^{\circ} \mathrm{C}\right)$.

Cropping calendar datasets based on typical national and sometimes sub-national planting and harvest dates for the 1990s or early 2000s (Sacks et al. 2010) were used to produce weighed monthly crop evapotranspiration values based on the crop coefficient $\left(\mathrm{K}_{\mathrm{c}}\right)$ at the four crop growth stages (initial, crop development, mid-season, late season). The cropping calendars were also used to estimate monthly values of the yield response factor $\left(\mathrm{K}_{\mathrm{y}}\right)$ (c.f. Section 2.2.3), for yield impact evaluations. The yield response factor is widely used in crop models and irrigation planning. Each crop growth stage has differing sensitivities to environmental stresses (e.g. grain filling and flowering, which occur midseason, are the most sensitive stages to water stress), which in turn affect the $\mathrm{K}_{\mathrm{c}}$ and $\mathrm{K}_{\mathrm{y}}$ values. Standard $\mathrm{K}_{\mathrm{c}}$ and $\mathrm{K}_{\mathrm{y}}$ values for maize (Online Resource 2) were obtained from the FAO (Allen et al. 1998). 
Subsequently, monthly water deficits were established from the difference between estimated monthly crop water requirements $\left(\mathrm{ET}_{\mathrm{c}}\right.$ ) and the monthly rainfall amounts having a probability of occurrence of $67 \%$ (i.e. minimum rainfall expected 2 years out of three). The latter is what is termed "design rainfall" when determining the sizing of RWH systems. The "design rainfall" accounts for significantly greater inter-annual variability present with rainfall, than with solar radiation or temperature used to estimate crop water requirements.

\subsubsection{Estimating Rainwater Harvesting System Design Requirements}

The design of RWH systems has been described in Critchley and Siegert (1991), yielding the following equation to evaluate the optimal catchment to cultivated area ratio (C:CA):

$$
\mathrm{C}: \mathrm{CA}=\frac{\left(E T_{c}-\text { Design Rainfall }\right)}{\left(\text { Design Rainfall }^{*} \text { Runoff Coefficient }^{*} \text { Efficiency }\right)}
$$

Here, the runoff coefficient is defined as the fraction of surface runoff to precipitation. A conservative value for the efficiency of in situ RWH systems was set to 0.6 , but it can reach up to 0.75 for such short slope catchments (Critchley and Siegert 1991). The efficiency factor takes into account the fact that not all harvested runoff can be used effectively by crops. The C:CA was calculated on a month-to-month basis, for both the historical and the future periods.

The maximum monthly value of the C:CA ratio required to fully bridge crop water deficits was determined. Fully bridging those deficits may require an excessively large catchment area, but farmers in arid environments already compensate by using very low cropping densities (e.g. Bationo et al. 1992). In our study, we vary spatially the C:CA ratio with respect to aridity, in order to integrate this reality. Hence, the use of larger catchment areas in those conditions does not necessarily reduce the availability of arable land for agricultural production. The aridity indices were determined using the De Martonne Aridity Index (which ranges from 0 for very dry to 100 for very humid environments) (de Martonne 1927) for both the historical and future period.

If the C:CA value fell within a reasonable range as per Table 1 (e.g. positive value $\leq 15: 1$ for an arid zone), then that value was kept as such. Otherwise, RWH was assumed to only partially bridge water deficits or be unnecessary. The gridded aridity indices were then used to re-assign the values of the C:CA ratio where only a partial bridging of the water deficit could be accomplished. The wettest areas were assigned the lowest ratio of $3: 1$.

The actual evapotranspiration $\left(\mathrm{ET}_{\mathrm{a}}\right)$ is equal to the design rainfall where there is no RWH. In the case where we use RWH, the C:CA ratios adjusted for aridity were used to estimate the amount of water actually harvested, which was then added to the design rainfall to obtain the total monthly $\mathrm{ET}_{\mathrm{a}}$ values.

Table 1 Assumed maximum allowable $\mathrm{C}$ :CA ratios by aridity zone

\begin{tabular}{ll}
\hline Aridity zone & Maximum allowable C:CA ratio \\
\hline Arid & $15: 1$ \\
Semi-arid & $10: 1$ \\
Dry sub-humid & $5: 1$ \\
Humid & $3: 1$ \\
\hline
\end{tabular}




\subsubsection{Estimating Impacts on Crop Yields}

The yield gap (or yield decrease from water deficits) expected in the cases with and without RWH was estimated on a monthly basis, using Eq. 4 (Doorenbos and Kassam 1979):

$$
\left(1-\frac{Y_{a}}{Y_{p}}\right)=K_{y}\left(\frac{E T_{a}}{E T_{c}}\right)
$$

Where $Y_{a}$ is the actual yield, $Y_{p}$ is the potential yield and $K_{y}$ is the yield response factor (c.f. Section 2.2.2). The maximum value of the potential yield decrease caused by water deficits within a growing season was selected for the determination of the potential to increase crop yields through bridging that water deficit with RWH. Due to the use of the 33rd percentile rainfall in the determination of $\mathrm{ET}_{\mathrm{a}}$, the monthly maximum potential yield decrease value effectively represents the minimum yield gap that will occur in one of three growing seasons. Finally, to evaluate the future performance of RWH with respect to their historical performance, Eq. 5 was developed:

$$
Y_{\text {Index }, t}=C A_{t}\left(1-\frac{Y_{\text {Gap }, t}}{100}\right)\left(1+\frac{Y_{\text {Increase }, t}}{100}\right)
$$

Where $\mathrm{Y}_{\text {Index,t }}$ is the yield index corrected for cropped area $\left(\mathrm{CA}_{\mathrm{t}}\right)$, percentage yield gap caused by water deficits $\left(\mathrm{Y}_{\mathrm{Gap}, \mathrm{t}}\right)$, and percentage yield increase associated with the use of RWH $\left(\mathrm{Y}_{\text {Increase, }}\right)$ for the time period $t$ (1986-2005 or 2046-2065). When $\mathrm{Y}_{\text {Index,2046-2065 }}<$

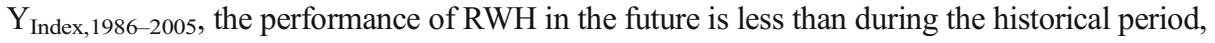
and would point towards the need for different climate change adaptation strategies for the concerned regions.

\subsection{Methodological Limitations}

As in any modelling study, the approach taken to evaluate RWH potential has inherent uncertainties. For instance, the selection of $\mathrm{K}_{\mathrm{c}}$ and $\mathrm{K}_{\mathrm{y}}$ can have a large impact on the estimation of crop water requirements. Standard values were selected, as a coarse-scale assessment of water requirements was conducted both spatially and temporally. This approach allows us to get a quick overview of which areas might suffer from greater water deficits, and is deemed essential to make climate-based agricultural water analyses relevant (Barron et al. 2003). The use of cropping calendars at a coarse resolution may lead to some regional anomalies in the results, especially at the borders between countries due to national-scale input data. Other uncertainties arise from GCM data. While we acknowledge that not all models produce reliable surface runoff from their land surface component (e.g. MRICGCM3), we chose to use gridded runoff data generated through GCMs as they guarantee a closed hydrological cycle (Weiland et al. 2012). We found that for the three models selected the runoff coefficient remained within reasonable bounds over rainfed Africa (i.e. between 0.05 and 0.3 , Online Resource 2).

Furthermore, using a coarse-scale empirical approach has the disadvantage of ignoring a wide range of processes involved in crop production, such as the increased nutrient use efficiency associated with higher water availability. This can lead to a significant underestimation of the potential of RWH to increase crop yields. This approach also ignores small-scale 
hydrological processes (e.g. crusting of soils in the Sahel), local socio-economic conditions, and the impact of daily rainfall variability.

Finally, the use of a field-scale equation to evaluate RWH potential with climate data at a much coarser resolution could lead to inaccuracies in the results. That being said, obtaining data to accurately model field-scale hydrological processes is impractical for a continentalscale assessment of RWH potential. The next section will also demonstrate that despite scale discrepancies, estimated C:CA from the coarse scale CMIP5 data is representative of the design requirements of reported local techniques.

\section{Results}

\subsection{Rainwater Harvesting Design Requirements}

Here it was assumed that the C:CA ratio for RWH generally corresponds to local cropping densities, which are expected to change in response to climate change independently of RWH adoption. Calculated C:CA ratios based on biophysical requirements and limitations (Fig. 2) correspond well with those observed in RWH systems in Africa. While reported C:CA values for RWH ideally sit between $1: 1$ and $3: 1$, some areas require greater ratios due to local conditions such as soil types and aridity (Critchley and Siegert 1991). For example, a typical zaï pit (30 cm diameter) density of 10,000 pits ha ${ }^{-1}$ in Northern Burkina Faso would represent a cropped area of about $7 \%$, or a C:CA of $13: 1$. This corresponds to 3 plants $\mathrm{m}^{-2}$ (typically three plants per pit), a value similar to 3.7 plants $\mathrm{m}^{-2}$ reported by Jones and Thornton (2003) for typical rainfed smallholder maize production systems in the tropics. Values as low as 2000 zaï pits ha ${ }^{-1}$ have been reported for millet in Niger (Bationo et al. 1992), as farmers in arid and semi-arid regions normally choose lower cropping densities.

BCC-CSM1-1

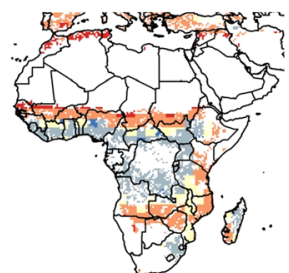

(a)

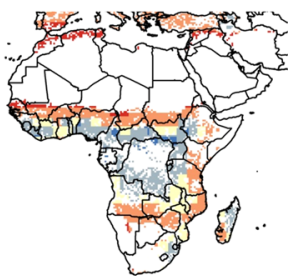

(d)
MIROC5

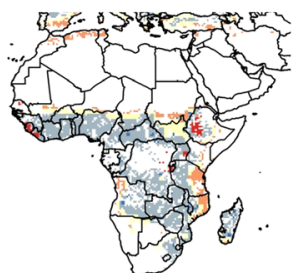

(b)

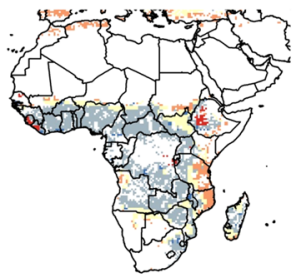

(e)

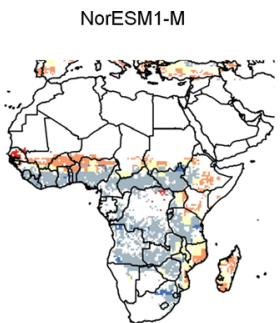

(c)

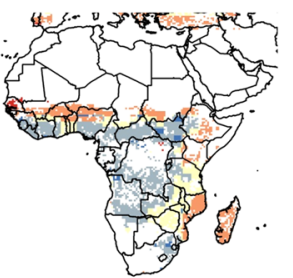

(f)
1986-2005

2046-2065

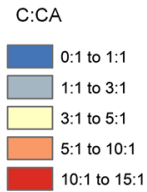

Fig. 2 Catchment area to cultivated area ratio (C:CA). Actual C:CA in consideration of optimal design requirements and maximum allowable ratio for the aridity of the region for the $1990 \mathrm{~s}(\mathbf{a}, \mathbf{b}, \mathbf{c})$ and the 2050s under RCP8.5 (d,e,f). GCMs used for calculations were BCC-CSM1-1(a,d), MIROC5 (b,e), and NorESM1-M (c,f) 
Here, the selected GCMs agree in a number of areas on the magnitude and direction of change in required cropping densities and C:CA ratios by the 2050s. Southern Africa is likely to be the most adversely affected region, while the Sahel does not see significant changes in RWH design requirements despite some projected increases in precipitation (c.f. Fig. 1). Areas of full agreement between models include Tanzania and Mozambique, while two out of three models show the need for greater C:CA ratios over Zambia and Zimbabwe.

\subsection{Mapping Crop Water Deficits Over Rainfed Areas}

Peak monthly crop water deficits for maize are found to already be important during the 1990s in the absence of RWH. These tend to increase with climate change over most rainfed regions of Africa, except over the Sahel and parts of Southern Africa in NorESM1-M, which could indicate a slight decrease in crop water deficits (Fig. 3). In comparison, Wada et al. (2013) show increases in irrigation water demand of $25 \%$ or more over most of Africa by the $2080 \mathrm{~s}$ under RCP8.5. Despite their use of a more complex modelling approach and their focus on the 2080s, their results complement the trend in changes in crop water deficits (generally between 1 and $25 \%$ ) presented here for the 2050 s.

\subsection{Stabilizing Crop Yields Through RWH}

The yield gaps in Fig. 4 represent the minimum yield gaps expected 1 in 3 years. There is good agreement between the three GCMs regarding yield gaps caused by water deficits in Eastern Africa, which are some of the highest on the continent. Areas of very low maize water productivity identified by Brauman et al. (2013) correspond well to the areas with the largest yield gaps in Fig. 4. While MIROC5 may underestimate water deficits suffered by crops during the growing season in the Sahel (i.e. projected excess water in all months), the two

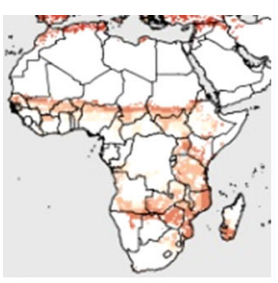

(a)

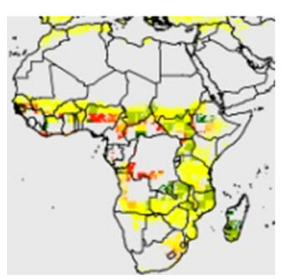

(d)

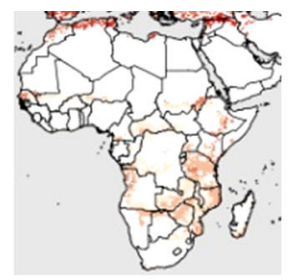

(b)

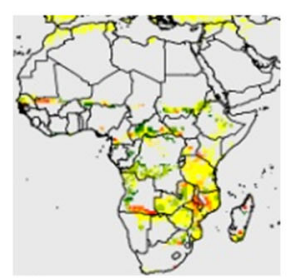

(e)

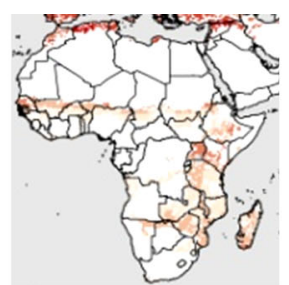

(c)

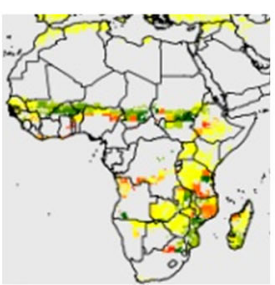

(f)
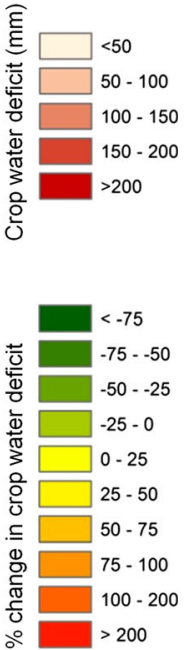

Fig. 3 Peak monthly water deficits for maize. The peak water deficits that a maize crop might experience for 1 month during the main growing season for the historical period (1986-2005) in $\mathrm{mm}(\mathbf{a}, \mathbf{b}, \mathbf{c})$, and the \% change (d,e,f) between that period and the future period (2046-2065, RCP8.5), were estimated using CMIP5 data (BCCCSM1-1[a,d], MIROC5 [b,e], and NorESM1-M [c,f]) under rainfed conditions without rainwater harvesting 


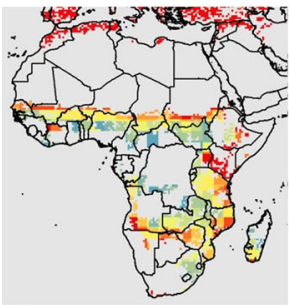

(a)

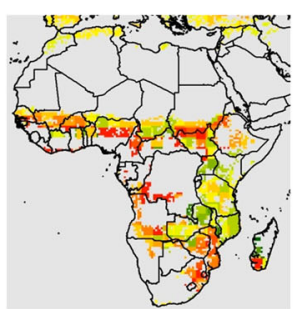

(d)

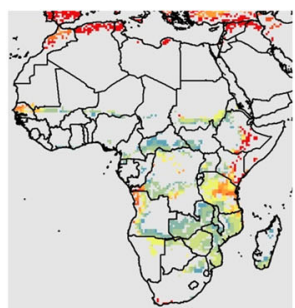

(b)

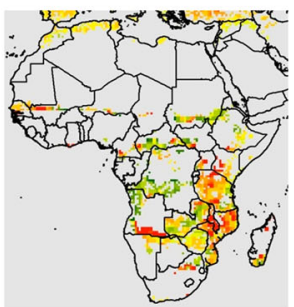

(e)

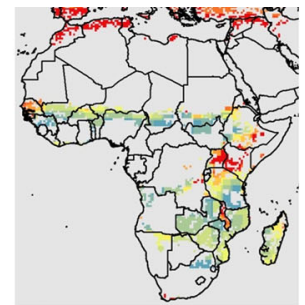

(c)

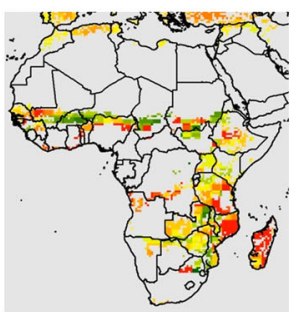

(f)

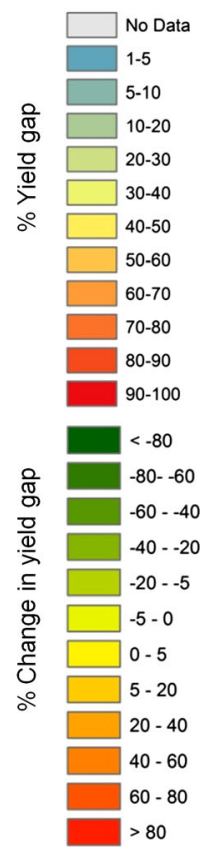

Fig. 4 Minimum yield gap attributable to water deficits for maize. The minimum percentage yield below potential (yield gap) that a maize crop might experience in the driest of 3 years for the historical period (19862005) (a,b,c), and the percentage change with respect to the future period (2046-2065) (d,e,f), were estimated using CMIP5 data (BCC-CSM1-1[a,d], MIROC5 [b,e], and NorESM1-M [c,f]) under rainfed conditions without rainwater harvesting

other models show a reasonable gradient over the region. For example, Northern Burkina Faso sees minimum yield gaps of 30-50\%, while the southernmost regions of the country are significantly less vulnerable. Over the Sahel, where models disagree on changes in precipitation, only BCC-CSM1-1 is projecting a worsening of the yield gap in the 2050s. Despite the very large yield gaps identified, once the use of RWH is taken into account most regions see a significant decrease in those yield deficits (Fig. 5).

Generally, the fraction of the yield gap caused by water deficits that can be bridged through RWH decreases by the 2050s, in regions where that yield gap increases. However, where aridity shifts to a higher aridity zone into the 2050s, the allowable catchment areas can be increased, leading to an increase in the benefits arising from the use of RWH. Overall, maize yield gaps which could be bridged through RWH range on average across Africa from 37 to $47 \%$ for the 1990s, and decrease to $28-36 \%$ for the 2050s (Fig. 5). Overall, RWH could maintain its ability to bridge a large part of water deficits in the future, and partially mitigate negative impacts of climate change.

Figure 6 shows that RWH is currently capable of stabilizing crop yields, and is likely to remain so in the future. In fact, where RWH is found to be able to stabilize crop yields for the 1990s, the mean potential yield increase associated with its use ranges between 9 and $39 \%$ (Fig. 4). The mean yield increase over Africa due to the use of RWH for maize is projected to grow in the 2050s to 14-50 \%, depending on the model. In parts of Eastern Africa, such as Tanzania, yield gaps remain too large for RWH to fully bridge them, but maize yield improvements can easily reach $25-50 \%$. Similarly, Elliott et al. (2014) found that irrigation 


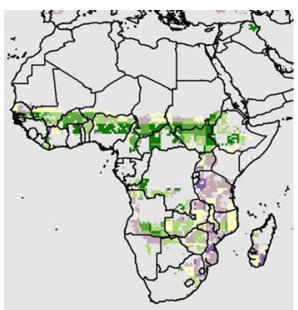

(a)

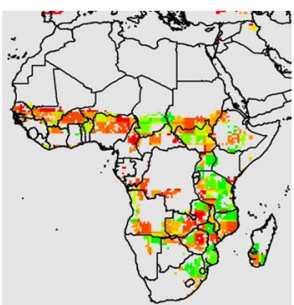

(d)

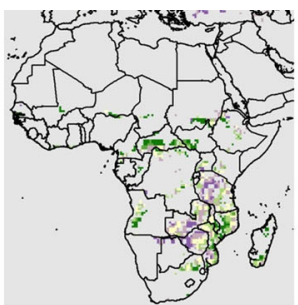

(b)

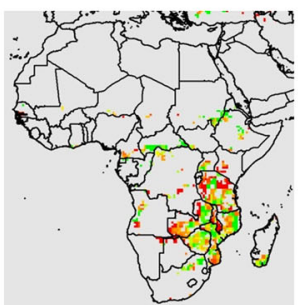

(e)
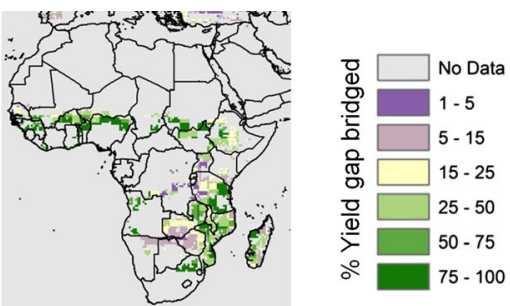

(c)

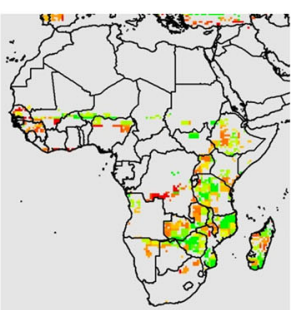

(f)

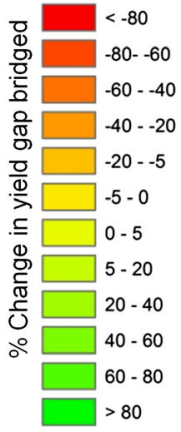

Fig. 5 Percentage of the minimum yield gap attributable to water deficits bridged through rainwater harvesting for maize. (a,b,c) represent the historical period (1986-2005) (a,b,c), and (d,e,f) show the change for the future period (2046-2065), estimated using CMIP5 data (BCC-CSM1-1[a,d], MIROC5 [b,e], and NorESM1-M [c,f])

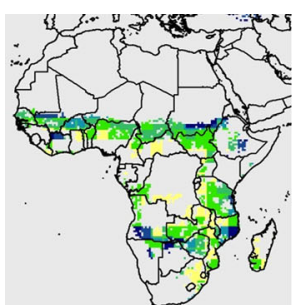

(a)

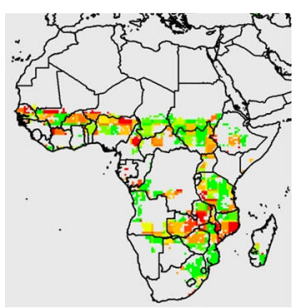

(d)

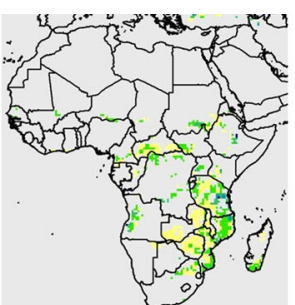

(b)

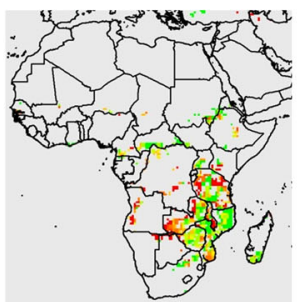

(e)
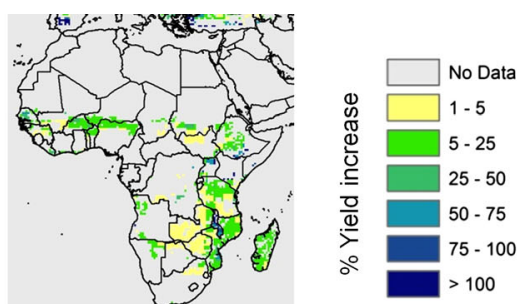

(c)

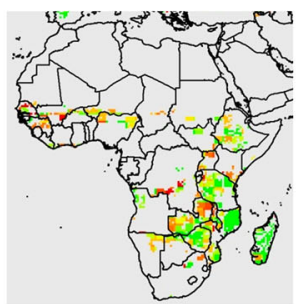

(f)

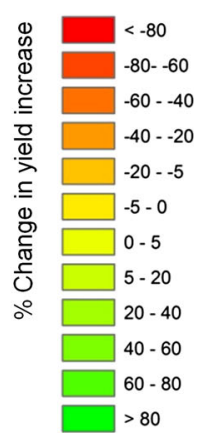

Fig. 6 Percentage yield increase attainable through rainwater harvesting. The minimum yield increase that a maize crop might experience in the driest of 3 years for the historical period (1986-2005) (a,b,c), and during the future period (2046-2065) (d,e,f), were estimated using the calculated design C:CA ratios and maximum crop water requirements throughout the main growing season. Three GCMs were used: BCC-CSM1-1 (a,b), MIROC5 (c,d), and NorESM1-M (e,f) 
could increase maize yields by up to $10 \%$ over wetter areas and over $50 \%$ in drier areas under RCP8.5 by 2100 .

\subsection{Prioritizing Areas for RWH Implementation}

While RWH can partially bridge maize yield gaps to various degrees across Africa today, it is likely to bring decreased benefits in the future in several regions (Fig. 7). Indeed, climate change will likely increase the vulnerability of maize crops to water stress in Southern Africa and particularly Zambia where all models agree to a decreasing of RWH performance based on the yield gaps, potential yield increase, and change in $\mathrm{C}$ :CA due to changes in aridity. Irrigation potential should be investigated in areas where RWH is unlikely to perform as well by the 2050s than under our current climate. On the other hand, RWH implementation for maize production should be prioritized in parts of Zimbabwe, Mozambique, Ethiopia, Tanzania, and a number of areas in the Sahel.

\section{Discussion}

Field-level experience has shown great potential for RWH to stabilize crop yields in otherwise harsh environmental conditions (e.g. Rockström et al. 2002; Sawadogo et al. 2008). At a larger scale, we found that the ability of RWH to bridge water deficits and to stabilize crop yields in Africa is projected to continue in the medium-term (2050s) under RCP8.5, despite some regions becoming more vulnerable. Where RWH is projected to perform more poorly in the future, irrigation should also be considered to adapt to climate change. However, in regions where groundwater resources are limited (MacDonald et al. 2012), RWH could still provide supplemental water for crop production by smallholder farmers.

In the semi-arid tropics and arid environments, RWH has already played an important role in stabilizing crop yields by mitigating the negative impacts of high evapotranspiration. However, those regions are projected to experience a higher frequency of lethal high temperatures which will likely not be mitigated by RWH. Hence, areas seeing a decrease in water deficits between the 1990s and the 2050s should not always be interpreted as potentially benefiting from climate change. This is particularly true in the Sahel, where an increased frequency of lethal high temperature events could have devastating effects on food production (Battisti and Naylor 2009).

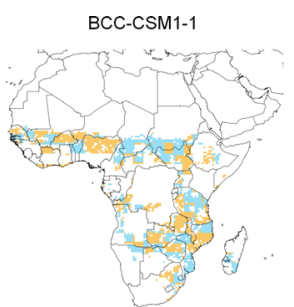

(a)

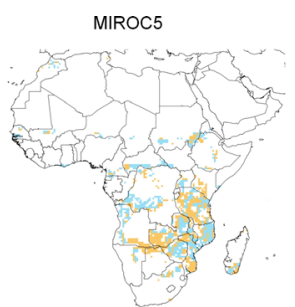

(b)

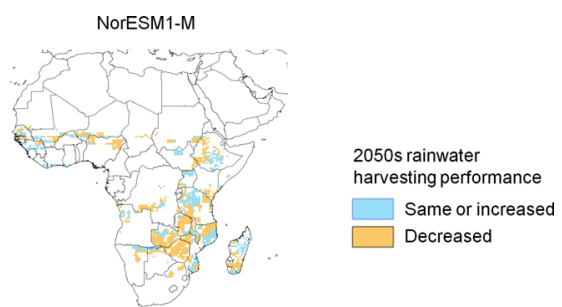

(c)

Fig. 7 Projected performance of rainwater harvesting (RWH) systems across Africa by the 2050s with respect to the 1990s, using three GCMs: BCC-CSM1-1 (a), MIROC5 (b), and NorESM1-M (c) 
While this study focused primarily on bridging water deficits, it is important to note that in several areas, RWH is also used in combination with nutrient management strategies (Rockström et al. 2002; Zougmoré et al. 2003), and can promote fertilizer utilization in areas of low adoption (Wakeyo and Gardebroek 2013). In Sahelian environments, soil fertility improvements could increase water use efficiency by three to five-folds (Breman et al. 2001). Moreover, RWH systems allow for the retention of water, for the conservation of nutrients through a reduction in soil losses associated with water erosion, and an overall reduction in risk to crop production. Hence, increases in yields associated with RWH go far beyond the simple bridging of the yield gap caused by water deficits, and the estimates presented here are only a fraction of the true benefits RWH can have on increasing crop yields in African drylands. There is still a need for higher spatial and temporal resolution studies to capture intra-seasonal distribution of rainfall and use of fertilization on the efficiency of RWH systems, amongst other factors (e.g. Pandey et al. 2013). In a context where we are unable to provide farmers reliable and consistent long-term inter- or intra-seasonal projections of changes in the climate, another possible benefit of RWH could be to help deal with precipitation variability by increasing the flexibility of cropping calendars. Specifically, RWH could extend the growing period by concentrating surface runoff associated with isolated rainfall events early or late during the season, and reduce the risk associated with the heavy reliance on those first few rains to determine when farmers are able to plant their crops.

Finally, one of the objectives of this study was to provide the "big picture" of the potential of RWH to stabilize crop yields, and reduce dependence on groundwater resources. In a context where African agriculture needs to be more productive to feed its population, these RWH benefits could be non-negligible. While agricultural development discourse has been heavily focused on the successes of the Green Revolution in Asia (and the expansion of irrigation), we still need to take into account the strikingly different situation of Africa today. If it is possible to bridge a minimum of $30-40 \%$ of yield gaps associated with crop water deficits simply with in situ RWH, the questions of energy requirements to access water, costs of implementation for wells or pumps, or overall low adaptive capacity, all become less of an issue for smallholder farmers. Despite in situ RWH strategies having the advantages of often being indigenous techniques, affordable, and widely applicable for smallholder farming, barriers to their adoption should be better understood to ensure their long-term sustainability (Pachpute et al. 2009).

\section{Conclusion}

This study set out to use GCM outputs to evaluate RWH potential, including the lesser-used surface runoff variable, and has shown promise towards providing useful information for adaptation planning at the national level. Indeed, the information provided here can be used to prioritize areas for RWH implementation and identify where complementary adaptation strategies might be necessary to fully address climate change impacts on crop water availability. Despite high levels of uncertainty associated with climate change projections, there is a need for smallholder farmers in sub-Saharan Africa to start coping more effectively with current climate variability. RWH represents a partial technical solution to the much more complex challenge of food insecurity, but offers a way to increase resilience to climate variability. Indeed, we find that RWH could bridge $31 \%$ of yield gaps attributable to water 
deficits under the projected climatic conditions of the 2050s, and increase maize yields by 14 $50 \%$ on average across Africa. Yet, the adoption rates of simple and often endemic technologies such as RWH stagnate without the proper training support of local governments and NGOs. RWH, especially in situ methods, offer the competitive advantage of requiring minimal financial, environmental, and social investments over other adaptation strategies such as the development of new drought-resistant crop varieties. A good understanding of local limitations to the adoption of RWH will be necessary to make them successful across the continent.

Acknowledgments This study was funded by a University of Leeds FIRS scholarship, and WAHARA (EU $7^{\text {th }}$ FP, grant no. 265570). We would also like to acknowledge the support of James Watson, William Brown, and Daniel Lacasse in contributing lines of code for the pre-processing of the CMIP5 climate data.

Author Contributions S. Lebel, P.M.F., and L.F. all contributed to the development of the original research idea. L.S.J. wrote the code for the pre-processing and regridding of the CMIP5 data, which was then adapted and used for the purpose of this analysis by S. Lebel and S. Lorenz. P.M.F. sourced the CMIP5 data. S. Lebel conducted the calculations. S. Lebel wrote the manuscript with significant inputs from L.F. and P.M.F.

Open Access This article is distributed under the terms of the Creative Commons Attribution 4.0 International License (http://creativecommons.org/licenses/by/4.0/), which permits unrestricted use, distribution, and reproduction in any medium, provided you give appropriate credit to the original author(s) and the source, provide a link to the Creative Commons license, and indicate if changes were made.

\section{References}

Adger WN, Barnett J, Brown K, Marshall N, O’Brien K (2012) Cultural dimensions of climate change impacts and adaptation. Nat Clim Change 3:112-117

Allen RG, Pereira LS, Raes D, Smith M (1998) Crop evapotranspiration - guidelines for computing crop water requirements. In: FAO (ed.) Irrigation and drainage paper., Rome, Italy

Barron J, Rockström J, Gichuki F, Hatibu N (2003) Dry spell analysis and maize yields for two semi-arid locations in east Africa. Agric For Meteorol 117:23-37

Barros VR, Field CB, Dokken DJ, Mastrandrea MD, Mach KJ, Bilir TE, Chatterjee M, Ebi KL, Estrada YO, Genova RC, Girma B, Kissel ES, Levy AN, MacCracken S, Mastrandrea PR, White LL, Niang I, Ruppel OC, Abdrabo MA, Essel A, Lennard C, Padgham J, Urquhart P (2014) Africa, climate change 2014: impacts, adaptation, and vulnerability. Part B: regional aspects. Contribution of working group II to the fifth assessment report of the intergovernmental panel of climate change. Cambridge University Press, Cambridge, pp 1199-1265

Bationo A, Christianson CB, Baethgen WE, Mokwunye AU (1992) A farm-level evaluation of nitrogen and phosphorus fertilizer use and planting density for pearl millet production in Niger. Fertil Res 31:175-184

Battisti DS, Naylor RL (2009) Historical warnings of future food insecurity with unprecedented seasonal heat. Science 323:240-244

Brauman KA, Siebert S, Foley JA (2013) Improvements in crop water productivity increase water sustainability and food security — a global analysis. Environ Res Lett 8:024030

Breman H, Groot JJR, van Keulen H (2001) Resource limitations in Sahelian agriculture. Glob Environ Chang 11:59-68

Bryan E, Deressa TT, Gbetibouo GA, Ringler C (2009) Adaptation to climate change in Ethiopia and South Africa: options and constraints. Environ Sci Policy 12:413-426

Cline WR (2007) Global warming and agriculture: impact estimates by country. Peterson Institute for International Economics

Critchley W, Siegert K (1991) Water harvesting: a manual for the design and construction of water harvesting schemes for plant production. In: FAO (Eed.) Rome

de Martonne E (1927) Regions of interior-basin drainage. Geogr Rev 17:397-414

Doorenbos J, Kassam AH (1979) Yield response to water. Irrigation and Drainage Paper 33

Elliott J, Deryng D, Müller C, Frieler K, Konzmann M, Gerten D, Glotter M, Flörke M, Wada Y, Best N, Eisner S, Fekete BM, Folberth C, Foster I, Gosling SN, Haddeland I, Khabarov N, Ludwig F, Masaki Y, Olin S, 
Rosenzweig C, Ruane AC, Satoh Y, Schmid E, Stacke T, Tang Q, Wisser D (2014) Constraints and potentials of future irrigation water availability on agricultural production under climate change. Proc Natl Acad Sci 111:3239-3244

Fox P, Rockström J (2000) Water-harvesting for supplementary irrigation of cereal crops to overcome intraseasonal dry-spells in the Sahel. Phys Chem Earth Part B Hydrol Oceans Atmos 25:289-296

Jasrotia AS, Majhi A, Singh S (2009) Water balance approach for rainwater harvesting using remote sensing and GIS techniques, Jammu Himalaya, India. Water Resour Manag 23:3035-3055

Jones PG, Thornton PK (2003) The potential impacts of climate change on maize production in Africa and Latin America in 2055. Glob Environ Chang 13:51-59

Kadam A, Kale S, Pande N, Pawar N, Sankhua R (2012) Identifying potential rainwater harvesting sites of a semi-arid, Basaltic Region of Western India, Using SCS-CN Method. Water Resour Manage, 1-18

Kay AL, Davies HN (2008) Calculating potential evaporation from climate model data: a source of uncertainty for hydrological climate change impacts. J Hydrol 358:221-239

MacDonald AM, Bonsor HC, Dochartaigh BÉÓ, Taylor RG (2012) Quantitative maps of groundwater resources in Africa. Environ Res Lett 7:024009

Mora C, Frazier AG, Longman RJ, Dacks RS, Walton MM, Tong EJ, Sanchez JJ, Kaiser LR, Stender YO, Anderson JM, Ambrosino CM, Fernandez-Silva I, Giuseffi LM, Giambelluca TW (2013) The projected timing of climate departure from recent variability. Nature 502:183-187

Muller C, Cramer W, Hare WL, Lotze-Campen H (2011) Climate change risks for African agriculture. Proc Natl Acad Sci U S A 108:4313-4315

Oudin L, Hervieu F, Michel C, Perrin C, Andréassian V, Anctil F, Loumagne C (2005) Which potential evapotranspiration input for a lumped rainfall-runoff model?: Part 2-towards a simple and efficient potential evapotranspiration model for rainfall-runoff modelling. J Hydrol 303:290-306

Pachpute J, Tumbo S, Sally H, Mul M (2009) Sustainability of rainwater harvesting systems in rural catchment of sub-Saharan Africa. Water Resour Manag 23:2815-2839

Pandey P, van der Zaag P, Soupir M, Singh V (2013) A new model for simulating supplemental irrigation and the hydro-economic potential of a rainwater harvesting system in humid subtropical climates. Water Resour Manag 27:3145-3164

Portmann FT, Siebert S, Döll P (2010) MIRCA2000; Global monthly irrigated and rainfed crop areas around the year 2000: a new high-resolution data set for agricultural and hydrological modeling. Global Biogeochem Cycles 24, GB1011

Rockström J, Falkenmark M (2015) Agriculture: increase water harvesting in Africa. Nature 519:283-285

Rockström J, Barron J, Fox P (2002) Rainwater management for increased productivity among small-holder farmers in drought prone environments. Phys Chem Earth Parts A/B/C 27:949-959

Rost S, Gerten D, Hoff H, Lucht W, Falkenmark M, Rockström J (2009) Global potential to increase crop production through water management in rainfed agriculture. Environ Res Lett 4:044002

Sacks WJ, Deryng D, Foley JA, Ramankutty N (2010) Crop planting dates: an analysis of global patterns. Glob Ecol Biogeogr 19:607-620

Sawadogo H, Bock L, Lacroix D, Zombré NP (2008) Restauration des potentialités de sols dégradés à l'aide du zai et du compost dans le Yatenga (Burkina Faso). Biotechnol Agron Soc Environ 12:279-290

Wada Y, Wisser D, Eisner S, Flörke M, Gerten D, Haddeland I, Hanasaki N, Masaki Y, Portmann FT, Stacke T, Tessler Z, Schewe J (2013) Multimodel projections and uncertainties of irrigation water demand under climate change. Geophys Res Lett 40:4626-4632

Wakeyo MB, Gardebroek C (2013) Does water harvesting induce fertilizer use among smallholders? Evidence from Ethiopia. Agric Syst 114:54-63

Weiland FCS, van Beek LPH, Kwadijk JCJ, Bierkens MFP (2012) On the suitability of GCM runoff fields for river discharge modeling: a case study using model output from HadGEM2 and ECHAM5. J Hydrometeorol 13:140-154

Zougmoré RB, Zida Z, Kambou NF (2003) Role of nutrient amendments in the success of half-moon soil and water conservation practice in semiarid Burkina Faso. Soil Tillage Res 71:143-149 